\title{
The Relationship between Physical Activity Levels and Psychological Resilience of University Students
}

\section{La relación entre niveles de actividad física y resiliencia psicológica de estudiantes universitarios}

\author{
Emrah Seçer \\ Physical Education and Sports, Erzincan Binali Yıldırım University, Erzincan, Turkey \\ ORCID: https://orcid.org/0000-0002-6683-680X \\ Yasemin Çakmak yildizhan \\ Physical Education and Sports, Erzincan Binali Yıldırım University, Erzincan, Turkey
}

ORCID: https://orcid.org/0000-0003-1937-6545

Received 0-12-20 Revised 01-25-20 Accepted 04-13-20 On line 06-29-20

*Correspondence

Email: eseraggon@gmail.com
Cite as:

Seçer, E., \& Çakmak Yildizhan, Y. (2020). The Relationship between Physical Activity Levels and Psychological Resilience of University Students. Propósitos y Representaciones, 8 (SPE2), e598. Doi: http://dx.doi.org/10.20511/pyr2020.v8nSPE2.598 


\section{Summary}

The aim of this study is to investigate the relationship between physical activity levels and psychological resilience of university students. The survey model, which is one of the quantitative research types, has been used in the research. The research group consists of 1734 students - 725 (41.8\%) males and 1009 (58.2\%) females) - studying at Erzincan Binali Yıldırım University. Psychological Resilience Scale (PRS) and International Physical Activity Questionnaire (IPAQ) data was used as a collection tool. Descriptive statistics, chi-square test of independence, independent samples t-test, Anova (Tukey), correlation, and regression tests have been used in the analysis of the data. As a result of the study, it has been seen that physical activity levels of men were higher than women and that there was no significant difference between the groups' psychological resilience. And when body mass indexes were examined, it was observed that physical activity levels of those with thin index were higher than those with normal and overweight index. In addition, a significant low-level positive correlation has been found between the physical activity levels. Physical activity level is a variable that predicts psychological resilience level.

Keywords: Physical Activity; Psychological Resilience; University Students.

\section{Resumen}

El objetivo de este estudio es investigar la relación entre los niveles de actividad física y la resistencia psicológica de los estudiantes universitarios. El modelo de investigación, que es uno de los tipos de investigación cuantitativa, se utilizó en la investigación. El grupo de investigación consta de 1734 estudiantes, 725 (41.8\%) hombres y 1009 (58.2\%) mujeres, que estudian en la Universidad Erzincan Binali Yıldırım. Los datos de la Escala de Resiliencia Psicológica (PRS) y el Cuestionario Internacional de Actividad Física (IPAQ) se utilizaron como herramienta de recolección. Se utilizaron estadísticas descriptivas, prueba de independencia de chi-cuadrado, prueba $\mathrm{t}$ de muestras independientes, Anova (Tukey), pruebas de correlación y regresión en el análisis de datos. Como resultado del estudio, se observó que los niveles de actividad física de los hombres eran más altos que las mujeres y que no había una diferencia significativa entre la resistencia psicológica de los grupos. Y, al examinar los índices de masa corporal, se observó que los niveles de actividad física de aquellos con un índice delgado eran más altos que aquellos con un índice normal y con exceso de peso. Además, se encontró una correlación positiva significativa de bajo nivel entre los niveles de actividad física. El nivel de actividad física es una variable que predice el nivel de resistencia psicológica.

Palabra clave: Actividad física; Resistencia psicológica; Estudiantes universitarios.

\section{Introduction}

Physical activity is defined as activities that result from energy expenditure using body functions in daily life, resulting in fatigue by increasing heartbeat and respiration (Savc1 et al., 2006).

Throughout the ages, physical activity has been an important issue for individuals to survive and transfer their characteristics to future generations. However, the growth of the world economy and the innovations brought by the technology age reduce the amount of energy consumed by individuals beside the benefits of saving time in working life, transportation and leisure activities (ÖZKAN, 2015). Although these developments contribute to individuals positively in terms of quality of life, they also cause some negative conditions. These include a variety of illnesses, such as excess weight, heart disease and diabetes, which can result from a sedentary lifestyle (Aslan et al., 2007). Regular physical activity occupies a very important place in life with a view to overcoming these negative conditions and minimizing health risks (Bek, 2008). In addition, because of the interaction with various groups through some activities, it provides important contributions to improve and maintain their mental and social health by 
improving individuals' communication skills, increasing their social adaptation and acceptance values, and contributing to the ability to overcome stress (Pinto et al., 1998).

When the important studies on physical activity in the world and in our country are also examined, it is observed that the activity levels of individuals have started to decrease and that this is an important threat. In a study conducted with university students, it was found that more than half of the students were not active enough and did activities below the recommended level (European Opinion Research Group, 2002). In another study with the participation of 15 European countries, it was concluded that the level of participation in physical activity was lower than expected (Ruiz et al., 2011). Also known as the HELENA study, which covers 9 European countries between 2006 and 2008, children with a mean age of 12.5-17.5 participated in the study. As a result of the study, it is stated that $56.8 \%$ of boys and $27.5 \%$ of girls comply with WHO activity level recommendation (Ünal et al., 2013). In our country, "Turkey Chronic Diseases and Risk Factors Prevalence Study" report published by the Ministry of Health in 2013 shows that physical activity is given great importance. According to the results explained in the report, it is reckoned that the level of physical activity in our country is not sufficient; therefore, various measures should be taken (World Health Organization, 2018). Today, 60\% of the world's population, which is around 7.44 billion, ignores the fact that physical activity is essential for health. However, one in 44 people worldwide is considered to lead an inactive life (Ağırkan, 2017).

According to the World Health Organization, physical activity affects individuals' physical and psychological conditions. Besides, both "Psychological Health" concept among the psychological, cognitive and emotional factors that affect participating in activities, and "Mental Wellness" concept in the WHO's health definition are noteworthy (Ağırkan, 2017).

An individual is considered to be not only a creature that performs physical actions, but a phenomenon that is an intellect and that undergoes positive or negative mental experiences in life. In order to be healthy, it is required to preserve this integrity in the face of negative experiences in life considering that it is necessary to be physically and spiritually strong as well. One of the components of the spiritual structure exhibited in the face of these negativities is psychological resilience, which can also be expressed as self-recovery (Öz \& Bahadir-Yılmaz, 2009).

Psychological Resilience is defined as the ability of an individual to overcome and adapt to these situations in spite of difficult conditions and negative experiences (Terzi, 2016).

Individuals who devote themselves to different areas of and have control over their lives, who regard negative experiences as opportunities for personal development rather than being a life-threatening factor, improve their well-being skills by using effective coping strategies to combat negative experiences. It is considered that these individuals have a high level of psychological resilience and maintain their physical and mental health (Karasar, 2012). The aim of this study is to determine the relationship between physical activity levels and psychological resilience of university students. For this purpose, the following questions were tried to be answered:

- Is there a relationship between physical activity levels and gender and BMI of university students?

- Is there a significant difference between university students' psychological resilience levels and gender and BMI?

- Do physical activity levels of university students predict their psychological resilience? 


\section{Material and Methods}

In this study, relational screening method, which is one of the quantitative research methods, has been used to investigate the relationship between physical activity levels and psychological resilience of university students.

Relational screening is a method that aims to determine whether there is a covariance between two or more variables and to determine the degree of this variance (Arıkan, 2004).

\section{Population and Sample}

The population of the study consists of students studying at Erzincan Binali Y1ldırım University in the 2017-2018 academic year. And the sample of the study is composed of 1734 students (725 (41.8\%) male and 1009 (58.2\%) female) who were selected by simple random sampling method and studied in the units located in the center of Erzincan Binali Y1ldırım University. Simple random sampling is a method where each element of the universe has equal chance of entering the sample and the value given to each element is equal in evaluation (Atienza, 2001). The distribution of students according to gender, age and body mass index variables are presented in Table 1.

Table 1.

Demographic Characteristics of the Students Participating in the Study

\begin{tabular}{cccc}
\hline Variable & Group & Frequency $(\mathrm{N})$ & Percentage (\%) \\
\hline \multirow{2}{*}{ Gender } & Male & 725 & 41.8 \\
& Female & 1009 & 58.2 \\
\multirow{2}{*}{ Age } & $17-19$ & 289 & 16.7 \\
& $20-21$ & 810 & 46.7 \\
& 22 and above & 635 & 36.6 \\
Body Mass Index & Thin & 187 & 10.8 \\
& Normal & 1280 & 73.8 \\
& Overweight & 267 & 15.4 \\
\hline
\end{tabular}

When Table 1 is examined, it is seen that $41.8 \%$ of the students participated in the study were male and $58.2 \%$ were female, $83.3 \%$ were 20 years and older and $73.8 \%$ were in the normal weight group.

\section{Data Collection Tool}

Data collection tool consists of 3 parts. In the first part, the Personal Information Form, which was created by the researchers and which includes questions to determine the demographic characteristics of the participants, was used. In the second part, International Physical Activity Questionnaire (Short Form), consisting of 7 questions, was used. The questionnaire was designed 
in 1996 by Austrian Dr. Michael Booth to determine the relationship between health and physical activity levels of the society. The International Physical Activity Evaluation Group designed the IPAQ in short and long forms using this questionnaire. IPAQ is announced to be valid and reliable as a result of the analyses using test re-test method in 12 countries and 14 research centers in 6 continents (Öztürk, 2005). The validity and reliability study of the questionnaire was carried out by Öztürk in a study conducted on university students and it was observed that the questionnaire was valid and reliable (Consultation, 2000). In the third part, Psychological Resilience Scale PRS developed by Terzi was used to determine the psychological resilience levels of individuals. PRS is a 5-point Likert-type scale that includes (0) strongly disagree, (1) disagree, (2) neither agree nor disagree, (3) agree and (4) strongly agree. In the PRS, which consists of 21 items expressing the individual's life and beliefs about themselves, reverse scores are made in the 2nd and 15th items. In order to determine the construct validity of this scale, exploratory and confirmatory factor analyses were conducted and it is specified that the scale consists of 21 items and 3 subdimensions. These dimensions are called self-commitment, control and challenge. While the Cronbach's alpha reliability coefficient for the whole scale was .76, the subscale for selfcommitment was .62, the control subscale for .69, and the challenge sub-dimension for .74. In this study, Cronbach's alpha reliability coefficient has been calculated as .74 for the whole scale.

\section{Analysis of Data}

During the research process, all analyses have been carried out with SPSS 22.00 program on computer.

All data during the research process were collected by the researcher after obtaining the necessary application and ethical permissions. During the research process, the scales were applied to 1870 students and primarily the missing data and the data of 110 students who were found to fill out the questionnaire systematically were excluded from the scope before being transferred to computer. Firstly, extreme value analysis, kurtosis and skewness values, Mahalanobis' and Cook's distance values of the data transferred to the computer were calculated and extracted from the data set of 26 students and the analyses were carried out on 1734 students. In addition, while the BMI of the students were being calculated, height and weight (BMI $=\mathrm{kg} /$ height ${ }^{2}$ ) of the students were calculated and they were categorized according to the classification specified by WHO (Tabaschnick \& Fidell, 2013). Descriptive analyses were carried out by calculating the mean, standard deviation, minimum and maximum values that describe physical activity levels in addition to frequency and percentage values in order to determine the personal characteristics of the students in the sample group.

In the descriptive analyses, Chi-square Independence Test was applied to check whether there is a relationship between the categorized values of the Physical Activity questionnaire used in the study and the personal characteristics of the students. In order to determine the relationship between physical activity and psychological resilience and to identify the difference between students' personal characteristics and psychological resilience, normality and homogeneity analyses were applied and the suitability of the variables for parametric analyses were reviewed. In this context, while independent sample t-test, One Way Anova, Correlation Analysis and Regression Analysis are applied for the variables having normal distribution and homogeneity, Tukey Test, one of the multiple comparison tests, has been used when there is a variance between the groups in the result of the One Way Anova in order to specify the source of the variance and which groups the variance is between. The results were evaluated at .05 and .01 levels.

\section{Results}

In this part of the study, which has been conducted to designate the relationship between physical activity levels and psychological resilience of university students, chi-square, t-test, Anova, 
correlation and regression analysis results have been used to identify the relationships between the descriptive analyses describing the characteristics of the participants' scale scores and variables.

Table 2.

Classification of Students' Physical Activity Scores from International Physical Activity Questionnaire

\begin{tabular}{ccccc}
\hline $\begin{array}{c}\text { Physical Activity Level (MET- } \\
\text { min/week) }\end{array}$ & $\mathrm{N}$ & Min. & Max. & $\begin{array}{c}\text { Average } \pm \text { Standard } \\
\text { Deviation }\end{array}$ \\
\hline İnactive (<600) & 300 & 89.50 & 594.00 & $376.27 \pm 123.04$ \\
Minimal Active (600-3000) & 847 & 612.00 & 2994.00 & $1662.98 \pm 692.31$ \\
Active (>3000) & 587 & 3012.00 & 10692.00 & $5073.42 \pm 1690.52$ \\
Total & 1734 & 89.50 & 10692.00 & $2594.88 \pm 2135.48$ \\
\hline
\end{tabular}

When the physical activity scores of the participants according to the MET values in Table 2 are examined, it has been concluded that the mean values of those who performed physical activity at an inactive level are $\bar{X}=376.27$, of those with minimal active physical activity are $\bar{X}$ $=1662.98$ and of those with very active physical activity are $\bar{X}=5073.42$.

Table 3.

Mean, Standard Deviation, Minimum, Maximum, Skewness and Kurtosis of Students' Scale Scores

\begin{tabular}{|c|c|c|c|c|c|c|c|}
\hline Factor & $\mathrm{N}$ & Min. & Max. & Ave. & S.d. & Skewness & Kurtosis \\
\hline Physical Activity & 1734 & 89.5 & 10692.0 & 2594.88 & 2135.48 & 1.13 & .85 \\
\hline $\begin{array}{l}\text { Psychological } \\
\text { Resilience }\end{array}$ & 1734 & 18 & 81 & 59.17 & 8.59 & -.53 & .57 \\
\hline
\end{tabular}

Table 3 reveals the descriptive statistics of students' scale scores. It is observed that the skewness and kurtosis coefficients of the scales are between -1.5 and +1.5 . Tabaschnick and Fidell (2013) state that if the scale's skewness and kurtosis values are between $-1.5-+1.5$, the data will exhibit normal distribution (Oğuz et al., 2018). Therefore, it is considered that parametric tests are suitable for comparing the data. 
Table 4.

Comparison of Physical Activity Level Groups According to Gender of Students

Physical Activity Level Group

(MET-min/week)

\begin{tabular}{|c|c|c|c|c|c|c|}
\hline \multicolumn{2}{|l|}{ Gender } & & & & \multirow{2}{*}{$\chi^{2}$} & \multirow{2}{*}{$\mathrm{p}$} \\
\hline & & Low & Medium & High & & \\
\hline \multirow{2}{*}{ Male } & $\mathrm{N}$ & 77 & 314 & 334 & & \\
\hline & $\%$ & 10.6 & 43.3 & 46.1 & & \\
\hline \multirow{2}{*}{ Female } & $\mathrm{N}$ & 223 & 533 & 253 & & \\
\hline & $\%$ & 22.1 & 52.8 & 25.1 & & \\
\hline \multirow{2}{*}{ Total } & $\mathrm{N}$ & 300 & 847 & 587 & 94.88 & $.00 * *$ \\
\hline & $\%$ & 17.3 & 48.8 & 33.9 & & \\
\hline
\end{tabular}

When the relationship between physical activity levels and gender of university students is examined, it is found that there is a relationship between the gender and physical activity levels of students $(\chi 2=94.88 ; p<.01)$. According to these results, $46.1 \%$ of male students are observed to be in high level and $52.8 \%$ of female students are in middle level physical activity group. According to this result, it can be stated that male students are more active than female students.

Table 1.

Comparison of Psychological Resilience Levels According to Gender of Students (t-test)

\begin{tabular}{|c|c|c|c|c|c|c|}
\hline Factor & Group & $\mathrm{N}$ & $\bar{X}$ & Ss & $\mathrm{t}$ & $\mathrm{p}$ \\
\hline \multirow{2}{*}{$\begin{array}{c}\text { Psychological } \\
\text { Resilience }\end{array}$} & Male & 725 & 59.58 & 8.62 & \multirow{2}{*}{1.68} & \multirow{2}{*}{.09} \\
\hline & Female & 1009 & 58.87 & 8.57 & & \\
\hline
\end{tabular}

In Table 5, in the results of the independent samples t-test used to determine whether students' psychological resilience levels differed significantly according to their gender, it has become apparent that the difference between the averages is not significant $\left(t_{1732}=-1.68 ; p>.05\right)$. 
Table 6.

Comparison of Physical Activity Level Groups According to Body Mass Index of Students

\section{Physical Activity Level Group}

\begin{tabular}{|c|c|c|c|c|c|c|}
\hline \multirow{2}{*}{\multicolumn{2}{|c|}{ Body Mass Index }} & \multicolumn{3}{|c|}{ (MET-min/week) } & \multirow{2}{*}{$\chi^{2}$} & \multirow{2}{*}{$\mathbf{p}$} \\
\hline & & Low & Medium & High & & \\
\hline \multirow{2}{*}{ Thin } & $\mathbf{N}$ & 50 & 98 & 39 & & \\
\hline & $\%$ & 26.7 & 52.4 & 20.9 & & \\
\hline \multirow{2}{*}{ Normal } & $\mathbf{N}$ & 213 & 616 & 451 & & \\
\hline & $\%$ & 16.6 & 48.1 & 35.2 & & \\
\hline \multirow{2}{*}{ Overweight } & $\mathbf{N}$ & 37 & 133 & 97 & & \\
\hline & $\%$ & 13.9 & 49.8 & 36.3 & 22.98 & $.00 * *$ \\
\hline \multirow{2}{*}{ Total } & $\mathbf{N}$ & 300 & 847 & 587 & & \\
\hline & $\%$ & 17.3 & 48.8 & 33.9 & & \\
\hline
\end{tabular}

When Table 6 is examined to determine whether there is a relationship between physical activity levels and body mass indexes of students, it is found that there is a relationship between physical activity level and BMI. $(\chi 2=22.98 ; \mathrm{p}<.01)$. It can also be claimed that activity level decreases as the index of the students with low activity level increases and activity levels increase as the indexes of the students with high activity level increase

\section{Table 7.}

Comparison of Psychological Resilience Levels of Students According to Body Mass Index (One Way Anova)

\begin{tabular}{ccccccccc}
\hline Factor & Group & $\mathrm{N}$ & $\overline{\mathrm{X}}$ & $\mathrm{Ss}$ & $\mathrm{Sd}$ & $\mathrm{F}$ & $\mathrm{p}$ & Tukey \\
& Thin (1) & 187 & 57.62 & 8.84 & & & & \\
& Normal (2) & 1280 & 59.45 & 8.50 & & & & \\
$\begin{array}{c}\text { Psychological } \\
\text { Resilience }\end{array}$ & $\begin{array}{c}\text { Overweight } \\
(3)\end{array}$ & 267 & 58.88 & 8.77 & & & & \\
& & & & & & & & \\
\hline
\end{tabular}

$* \mathbf{p}<.05$ 
In the results of the one-factor ANOVA used to determine whether the students' psychological resilience levels differ significantly according to their body mass indexes, it has

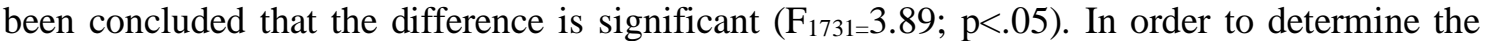
difference between the means, the Tukey test which is one of the multiple comparison tests has been applied and the psychological resilience levels of those with normal index $\bar{X}: 59.45$ have been found to be significantly higher than $\bar{X}: 57.62$ for those with thin index.

A two-stage analysis has been applied to identify whether physical activity level is a significant predictor of psychological resilience in university students. Correlation analysis was applied in the first stage and the relationships between the variables were determined and in the second stage the regression analysis was used to examine the predictive relations. The results of the correlation analysis are presented in Table 8 .

Table 8.

Relationship Between Physical Activity Level and Psychological Resilience

\begin{tabular}{cccccc}
\hline & & $\begin{array}{c}\text { Self- } \\
\text { Commitment }\end{array}$ & Challenge & Control & $\begin{array}{c}\text { Total } \\
\text { Psychological } \\
\text { Resilience }\end{array}$ \\
\hline Physical Activity & $\mathrm{r}$ & $.14^{* *}$ & $.13^{* *}$ & $.12^{* *}$ & $.17^{* *}$ \\
& $\mathrm{p}$ & .00 & .00 & .00 & .00 \\
\hline
\end{tabular}

$* \mathrm{p}<.01$

When Table 8 is examined, it has been found that there are low-level positive relationships between physical activity and the self-commitment sub-dimension of psychological resilience $(\mathrm{r}=.14, \mathrm{p}<.01)$, physical activity and challenge sub-dimension $(\mathrm{r}=.13, \mathrm{p}<.01)$, physical activity and control sub-dimension $(\mathrm{r}=.12, \mathrm{p}<.01)$ physical activity and total psychological resilience $(\mathrm{r}=.17, \mathrm{p}<.01)$.

Since significant relationships between variables were noted in correlation analysis, simple linear regression analysis was used to analyze the predictive relationships and the findings are presented below.

Table 9.

Results of Regression Analysis of Students' Physical Activity Levels Predicting Psychological Resilience Levels

\begin{tabular}{cccccccc}
\hline Model & B & S. Error & $\beta$ & $\mathrm{t}$ & $\mathrm{p}$ & $\mathrm{R}$ & $\mathrm{R}^{2}$ \\
\hline (Constant) & 57.33 & .320 & & 179.20 & .00 & & \\
Physical Activity & .001 & .000 & .176 & 7.42 & .00 & .17 & .3 \\
\hline
\end{tabular}

$\mathrm{R}=.17, \mathrm{R}^{2}=.3, \mathrm{~F}=55.14, \mathrm{p}<.01$

Table 9 shows that physical activity level is a positive and significant predictor of psychological resilience among university students and physical activity level explains $.03 \%$ of psychological resilience among university students $\left(\mathrm{R}=.17, \mathrm{R}^{2}=.03, \mathrm{~F}=55.14, \mathrm{p}<.01\right)$. When the 
obtained values are examined, it is possible to argue that one-unit change in the physical activity level will cause an increase of .17 units in the psychological resilience level, and that the physical activity level is an important predictor in terms of psychological resilience in university students.

\section{Discussion}

In the research, it has been monitored that there is a relationship between the gender variable and physical activity levels of the students and male students have higher activity level than female students. When the related literature is researched, it is seen that in their study which investigates the university students' status of physical activity and effects of physical activity on heart health, Oğuz et al. (2018) concluded that male students has higher levels of physical activity than females. In the study that Papathanasiou et al. (2015) conducted where 1249 university students participated in Greece and in various studies of Zavonec et al. (2015) on university students, it has been found that physical activity levels of male students are significantly higher than female students. Similarly, in another study conducted by Haase et al. (2004), which is one of the most comprehensive studies, and which compares the physical activity levels of 19,298 university students in 23 different countries, it has been found that male students have higher levels of physical activity than female students. In a study conducted by Savc1 et al. (2006) aiming to observe the physical activity levels of university students, it has been found that male students have significantly higher physical activity levels than female students.

In the research, no significant difference has been found between the psychological resistance levels of university students according to gender variable. When the literature is examined, it is seen that the number of studies to determine the difference between psychological resilience and gender is quite high. In the study conducted by Vergili (2018) aiming to identify the relationship between university students' attachment styles and their psychological resilience, 150 participants participated in the study and found no difference between gender and psychological resilience. In this study, it is also emphasized that males' psychological resilience level is expected to be high. This prejudice results from the opinion that men are individuals who take care of the house and take responsibility in life; women are said to be delicate and need protection. It is seen that similar results were found in the studies conducted by Y1lmazer (2017) in which the candidate teachers preparing for the public personnel selection exam attended and by Ağırkan (2017) where university students participated. Likewise, in a study conducted by Kumar et al. (2016), 72 elite volleyball players have been found to show no significant difference between gender and psychological resilience. In addition, it has been stated that female and male volleyball players having similar fitness level, sporting skills and emotional characteristics may cause this result.

In our study, a relationship has been found between BMI variable and physical activity levels of university students. It is observed that physical activity level decreases as the weight increases in students with low activity level, and that physical activity level increases as the weight increases in students with high activity level (table 6). Again, regarding various studies examined in the literature, in the study by Ipek (2018) conducted with the participation of 1970 university students, while it was observed that there is a significant difference between the levels of physical activity according to BMI, the students with overweight index were more active than the students with normal and thin index. In addition, $61 \%$ of overweight students, $47 \%$ of normal overweight students and $29 \%$ of thinner students are in the active category. In the study conducted by Parlaktaş (2018) in which secondary school students participated, a significant difference was found between the BMI and physical activity levels of the students, whereas the physical activity levels of the students with a thin index were significantly higher than those with both normal and overweight index. 
Similarly, in a different study in which secondary school students participated, physical activity levels of the students are found to be significantly higher than those with thin index and those with normal index (Kara, 2017). Bradbury et al. (2017) observed in their study held on adults in the UK that there is an inverse relationship between BMI and physical activity in adults and that body fat ratio decreases with increasing physical activity.

In our study, a significant difference has been found between the psychological resilience levels of university students according to BMI variable. It is observed that the psychological resilience levels of the participants in the normal index are significantly higher than those in the thin index. In a study conducted by Aslan (2018) with 150 participants in Kocaeli province, body mass index and psycho-social factors were examined in women and it was concluded that there is a significant difference between weight and psychiatric history. In another study conducted by Altunoğlu et al. (2015), it is found that there is a relationship between obesity and depression in middle-aged individuals and that obesity or overweight could negatively affect their psychological resilience.

In the research, it has been concluded that there is a low-level positive relationship between physical activity levels and psychological resilience of university students. In addition, it is observed that physical activity level significantly predicted psychological resilience. According to the related literature such as in a study conducted by IIlhan (2017) on 300 university students where the relationship between exercise participants and psychological resilience and different variables is investigated, a significant difference has been found between weekly exercise frequency and psychological resilience. In a study conducted by Schall et al. (2011), it was determined that professional activity contributed positively to psychological resilience level. In studies conducted with different age groups, Babis and Gangwisch (2009) with 14,594 adolescent participants and Dishman et al. (2006) with 1,250 female high school students observed that regular sports have positive effects on psychology and increase psychological power. In a study held by Şahin et al. (2012) it is suggested that students should participate in activities regularly as participation in physical activities strengthens the physical structure of the individual and as a result contributes to the individual in terms of psychological support to the struggle against difficulties.

When the research findings are investigated from a different perspective, the high level of psychological resilience in individuals may indicate that negative emotions such as depression, worry and anxiety are experienced at a low level (Çavaş Bali, Ekim 2017; Terzi, 2005; Florian et al., 1995; Rhodewalt \& Zone, 1989). This situation should be supported by various research findings. In studies conducted by Arslan, et al. (2018) on 140 university students and by Iş1k, et al. (2015) on 300 university students, a weak negative relationship has been found between the level of physical activity and depression. Mammen and Faulkner (2013) stated that increasing the level of physical activity is an important strategy in reducing the risk of depression in their systematic review. In another study, Carless and Douglas (2008) stated that regular physical activity is very useful in the fight against obesity, chronic diseases and health and emphasized that sport contributes positively to individuals' identity acquisition and plays an important role in the prevention of mental disorders.

When the studies examining the relationship between physical activity and psychological resilience are evaluated in general, it is possible to claim that there is a negative relationship between physical activity and depression and anxiety, and in line with these results, we can suggest that individuals who perform physical activity have high psychological resilience.

As seen in all these studies, physical activity is regarded to be an important factor with positive effects on the psychology of individuals. In today's technology age, it is considered to be inevitable to encounter difficulties as individuals are thought to have different relationships in 
many environments such as business life, social life, family life etc. At this stage, individuals may become vulnerable to psychological disorders as a result of psychological and physical fatigue. In order to avoid this situation, it is very important to consider physical activity as a hobby and to make good use of leisure time with various activities.

\section{Conclusion}

In the research, it has been concluded that there is a relationship between gender variable and physical activity level and that male students are more active than female students. It is also observed that there is no difference between the gender variable and students' psychological resilience. There is a relationship between BMI variable and physical activity level, and it has been ascertained that those in thin index are more active than those in normal index and overweight index. It has also been found that there is a significant difference between BMI and students' psychological resilience levels and that those in the normal index category are significantly higher than those in the thin index category. The most important result of the research is that there is a positive low-level relationship between physical activity level and psychological resilience level and that physical activity level is a variable that predicts psychological resilience level.

- In the light of the findings of the research;

- The relationship between exercise and psychological resilience can be examined by using experimental research method.

- Psychological resilience levels of performance athlete groups can be examined.

- The effect of psychological resilience levels of athletes on their performances can be examined.

\section{References}

Ağırkan, M. (2017). The relationship between value orientations and psychological resilience levels of university students. Master's Thesis, Erzincan University, Erzincan.

Alpözgen, A.Z., \& Özdinçer, A.R. (2006). Physical activity and protective effects. HSP, 3(1), 66-.

Altunoğlu, E. G., Müderrisoğlu, C., Erdenen, F., Ülgen, E., \& Memiş, İ. (2015). The Association between Obesity-Insulin Resistance and Depression-Anxiety: One Center, CrossSectional Study. Istanbul Medical Journal, 16(2).

Arıkan, R. (2004). Araştırma Teknikleri Ve Rapor Hazırlama, Asil Yayın Dağıtım.

Aslan, N. (2018). Determination of psychosocial factors related to the body mass index in women. Journal of Health Sciences of Kocaeli University, 4(2), 50-56.

Aslan, U. B., Livanelioglu, A., \& Aslan, S. (2007). Evaluation of physical activity level in undergraduate students by two methods. Fizyoterapi Rehabilitasyon, 18(1), 11.

Atienza, A. A. (2001). Home-based physical activity programs for middle-aged and older adults: Summary of empirical research. Journal of Aging and Physical Activity, 9(s1), S38-S58.

Babiss, L. A., \& Gangwisch, J. E. (2009). Sports participation as a protective factor against depression and suicidal ideation in adolescents as mediated by self-esteem and social support. Journal of Developmental \& Behavioral Pediatrics, 30(5), 376-384.

Bek, N. (2008). Fiziksel aktivite ve sağlı̆̆ımız. Sağlık Bakanlığı Yayın, 730.

Bradbury, K. E., Guo, W., Cairns, B. J., Armstrong, M. E., \& Key, T. J. (2017). Association between physical activity and body fat percentage, with adjustment for BMI: a large cross-sectional analysis of UK Biobank. BMJ open, 7(3), e011843. 
Carless, D., \& Douglas, K. (2008). Narrative, identity and mental health: How men with serious mental illness re-story their lives through sport and exercise. Psychology of sport and exercise, 9(5), 576-594.

Consultation, W. H. O. (2000). obesi'i'y: preventing and managing the global epidemic.

Çavaş Bali S. (Ekim 2017). Psikolojik Dayanıklılı̆̆ın Psikopatolojik Yansımaları [Panel]. 53.Ulusal Psikiyatri Kongresi, Türkiye Psikiyatri Derneği, Bursa/Merinos AKKM.

Dishman, R. K., Hales, D. P., Pfeiffer, K. A., Felton, G. A., Saunders, R., Ward, D. S., ... \& Pate, R. R. (2006). Physical self-concept and self-esteem mediate cross-sectional relations of physical activity and sport participation with depression symptoms among adolescent girls. Health Psychology, 25(3), 396.

European Opinion Research Group. (2002). Special Eurobarometer 183-6, 2002. Physical Activity, wave, 58, 1-49.

Florian, V., Mikulincer, M., \& Taubman, O. (1995). Does hardiness contribute to mental health during a stressful real-life situation? The roles of appraisal and coping. Journal of personality and social psychology, 68(4), 687.

Haase, A., Steptoe, A., Sallis, J. F., \& Wardle, J. (2004). Leisure-time physical activity in university students from 23 countries: associations with health beliefs, risk awareness, and national economic development. Preventive medicine, 39(1), 182-190.

Işık, Ö., Özarslan, A., \& Bekler, F. (2015). The correlation among physical activity, quality of sleep and depression among the university students. Niğde Univ J Phys Educ Sport Sci, 9, 65-73.

Illhan, A. (2017). The Relationship between psychological resilience, dispositional flow and motivation in the exercise participants. Phd Thesis, Ege University, İzmir.

İpek, C. (2018). The investigation of relationship between the physical activity level and body composition in young adults. Master's Thesis, Selcuk University, Konya.

Kara, M. G. (2017). Investigation of Physical Activity Levels and Obesity Awareness Levels of Middle School Students. Master's Thesis, İnönü University, Malatya.

Karasar, N. (2012). Bilimsel araştırma yöntemi.(24. Basım). Ankara: Nobel Yayın Dağıtım.

Kumar, S., Singh, N. S., \& Mitra, S. (2016). Comparison of mental toughness between male and female volleyball players of 12th south Asian games. International Journal of Applied Research, 2(6), 268-270.

Mammen, G., \& Faulkner, G. (2013). Physical activity and the prevention of depression: a systematic review of prospective studies. American journal of preventive medicine, 45(5), 649-657.

Oğuz, S, Çamcı, G, \& Yılmaz, RK. (2018). State of university students' physical activity and knowing the effect of physical activity on heart health. Gümüşhane University Journal of Health Sciences, 7(1), 54-61.

Öz, F., \& Bahadır-Y1lmaz, E. (2009). A significant concept in protecting mental health: resilience. Hacettepe University Faculty of Health Sciences Nursing Journal, 16(3), 82-89.

ÖZKAN, A. K. (2015). Kırıkkale Üniversitesi öğrencilerinin fiziksel aktivite düzeyinin pedometre ile belirlenmesi Examination of physical activity level of Kirikkale University students pedometer.

Öztürk, M. (2005). A research on reliability and validity of international physical activity questionnaire and determination of physical activity level in university students. Master's Thesis, Hacettepe University, Ankara.

Papathanasiou, G., Zerva, E., Zacharis, I., Papandreou, M., Papageorgiou, E., Tzima, C., ... \& Evangelou, A. (2015). Association of high blood pressure with body mass index, smoking and physical activity in healthy young adults. The open cardiovascular medicine journal, 9,5 .

Parlaktaş, Y. (2018). The Relationship between physical activity level and academic achievement in middle school 8th grade students. Master's Thesis, Kırıkkale University, Kırıkkale. 
Pinto, B. M., Cherico, N. P., Szymanski, L., \& Marcus, B. H. (1998). Longitudinal changes in college students' exercise participation. Journal of American College Health, 47(1), 2327.

Rhodewalt F, \& Zone JB. (1989). Appraisal of life change, depression and illness in hardy and nonhardy women. Journal of Personality and Social Psychology, 56, 81-88.

Ruiz, J. R., Ortega, F. B., Martínez-Gómez, D., Labayen, I., Moreno, L. A., De Bourdeaudhuij, I., \& Widhalm, K. (2011). Objectively measured physical activity and sedentary time in European adolescents: the HELENA study. American journal of epidemiology, 174(2), 173-184.

Savc1, S., Öztürk, M., Arıkan, H., İnal İnce, D., \& Tokgözoğlu, L. (2006). Physical activity levels of university students. Archives of the Turkish Society of Cardiology, 34(3), 166-172.

Schaal, K., Tafflet, M., Nassif, H., Thibault, V., Pichard, C., Alcotte, M., ... \& Toussaint, J. F. (2011). Psychological balance in high level athletes: gender-based differences and sportspecific patterns. PloS one, 6(5), e19007.

Serel Arslan S, Alemdaroğlu İ, Öksüz Ç, Karaduman AA, Tunca Yılmaz, Ö. (2018). The effect of physical activity on academic success and depression in young individuals. Journal of Occupational Therapy And Rehabilitation, 6(1), 37-42.

Şahin, M., Yetim, A. A., \& Çelik, A. (2012). Physical Activity and Sport as a Preventive Factor in Building Resilience. The Journal of Academic Social Science Studies, 5(8), 373-380.

Tabaschnick, B. G., \& Fidell, L. S. (2013). Using multivariate statistics (6th Edit.).

Terzi, Ş. (2005). Psychological hardiness model relating to subjective well being. Phd Thesis, Gazi University, Ankara.

Terzi, Ş. (2016). Developing the psychological hardiness scale: the validity and reliability study. The Journal of Happiness \& Well-Being, 4(2), 165-182.

Ünal, B., Ergör, G., Horasan, G. D., Kalaça, S., \& Sözmen, K. (2013). Türkiye kronik hastalıklar ve risk faktörleri sıklığı çalışması. Ankara: Să̆glk Bakanlı̆̆ .

Vergili, M. (2018). The Relationship between attachment types and psychological resilience in university students. Master's Thesis, Üsküdar University, İstanbul.

World Health Organization. (2018). [http://www.who.int/topics/physical_activity/en/] [Acceseed on 24 May, 2018].

Y1lmazer, F. (2017). Resilience and bornout of the teachers who prepared for kpss depending test anxiety. master's thesis, üsküdar university, istanbul.

Zanovec, M., Lakkakula, A. P., Johnson, L. G., \& Turri, G. (2009). Physical activity is associated with percent body fat and body composition but not body mass index in white and black college students. International journal of exercise science, 2(3), 175. 